Atmos. Chem. Phys., 13, 10113-10123, 2013

www.atmos-chem-phys.net/13/10113/2013/

doi:10.5194/acp-13-10113-2013

(c) Author(s) 2013. CC Attribution 3.0 License.

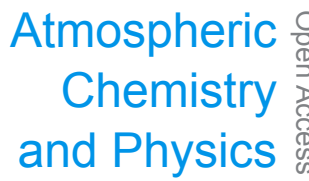

\title{
Stratospheric $\mathrm{O}_{3}$ changes during 2001-2010: the small role of solar flux variations in a chemical transport model
}

\author{
S. S. Dhomse ${ }^{1}$, M. P. Chipperfield ${ }^{1}$, W. Feng ${ }^{1}$, W. T. Ball ${ }^{2}$, Y. C. Unruh ${ }^{2}$, J. D. Haigh ${ }^{2}$, N. A. Krivova ${ }^{3}$, S. K. Solanki ${ }^{3,4}$, \\ and A. K. Smith ${ }^{5}$ \\ ${ }^{1}$ School of Earth and Environment, University of Leeds, Leeds, UK \\ ${ }^{2}$ Physics Department, Blackett Laboratory, Imperial College London, London, UK \\ ${ }^{3}$ Max-Planck-Institut für Sonnensystemforschung, Katlenburg-Lindau, Germany \\ ${ }^{4}$ School of Space Research, Kyung Hee University, Yongin, Gyeonggi, South Korea \\ ${ }^{5}$ National Center for Atmospheric Research, Boulder, CO, USA \\ Correspondence to: S. S. Dhomse (s.s.dhomse@leeds.ac.uk)
}

Received: 26 March 2013 - Published in Atmos. Chem. Phys. Discuss.: 8 May 2013

Revised: 5 September 2013 - Accepted: 6 September 2013 - Published: 15 October 2013

\begin{abstract}
Solar spectral fluxes (or irradiance) measured by the SOlar Radiation and Climate Experiment (SORCE) show different variability at ultraviolet (UV) wavelengths compared to other irradiance measurements and models (e.g. NRL-SSI, SATIRE-S). Some modelling studies have suggested that stratospheric/lower mesospheric $\mathrm{O}_{3}$ changes during solar cycle 23 (1996-2008) can only be reproduced if SORCE solar fluxes are used. We have used a 3-D chemical transport model (CTM), forced by meteorology from the European Centre for Medium-Range Weather Forecasts (ECMWF), to simulate middle atmospheric $\mathrm{O}_{3}$ using three different solar flux data sets (SORCE, NRL-SSI and SATIRE-S). Simulated $\mathrm{O}_{3}$ changes are compared with Microwave Limb Sounder (MLS) and Sounding of the Atmosphere using Broadband Emission Radiometry (SABER) satellite data. Modelled $\mathrm{O}_{3}$ anomalies from all solar flux data sets show good agreement with the observations, despite the different flux variations. The off-line CTM reproduces these changes through dynamical information contained in the analyses. A notable feature during this period is a robust positive solar signal in the tropical middle stratosphere, which is due to realistic dynamical changes in our simulations. Ozone changes in the lower mesosphere cannot be used to discriminate between solar flux data sets due to large uncertainties and the short time span of the observations. Overall this study suggests that, in a CTM, the UV variations detected by SORCE are not necessary to reproduce observed stratospheric $\mathrm{O}_{3}$ changes during 2001-2010.
\end{abstract}

\section{Introduction}

The Sun is the primary source of energy to the Earth's atmosphere, so it is essential to understand the influence that solar flux variations may have on the climate system. This can be studied by investigating the effect of $11 \mathrm{yr}$ solar flux variations on the atmosphere. Although total solar irradiance (TSI) shows only a small variation $(\sim 0.1 \%$ per solar cycle $)$, significant (up to $100 \%$ ) variations are observed in the ultraviolet (UV) region of the solar spectrum. In a "top-down" mechanism, these UV changes are thought to modify middle atmospheric (lower mesospheric and stratospheric) $\mathrm{O}_{3}$ production, thereby indirectly altering background temperatures (for a review see Gray et al., 2010). These temperature changes can then modulate upward propagating planetary waves, and amplify the solar signal in stratospheric $\mathrm{O}_{3}$ and temperatures. The temperature changes will also affect the rates of chemical reactions which control ozone.

This mechanism has been well accepted. For example, using Solar Back-scatter Ultraviolet Radiometer (SBUV, 1979-2003) and Stratospheric Aerosol and Gas Experiment II (SAGE II, 1984-2003) satellite data, Soukharev and Hood (2006) derived nearly $+3 \% \mathrm{O}_{3}$ variation in the upper stratosphere/lower mesosphere $(45-55 \mathrm{~km})$ with no solar signal in the tropical middle stratosphere $(30-40 \mathrm{~km})$. Randel and $\mathrm{Wu}$ (2007) estimated a similar signal using SAGE I and SAGE II (1979-2005) data. However, using Halogen Occultation Experiment (HALOE, 1992-2005) data, both Soukharev and Hood (2006) and Remsberg (2008) found 
a negligible $(<1 \%) \mathrm{O}_{3}$ solar signal in the upper stratosphere/lower mesosphere and a positive solar signal in the middle stratosphere.

These differences in the upper stratospheric and lower mesospheric ozone solar signal between SBUV, SAGE and HALOE have been attributed to the shorter time span ( $<14 \mathrm{yr}$ ) of HALOE measurements (Soukharev and Hood, 2006). However, using an off-line 3-D chemical transport model (CTM) forced with European Centre for MediumRange Weather Forecasts (ECMWF) (re)analysis meteorological data and NRL-SSI solar fluxes (Lean et al., 1997), Dhomse et al. (2011) found that their modelled solar signal was in better agreement with HALOE than SBUV or SAGE. Also, although some coupled 2-D and 3-D Chemistry Climate Models (CCMs) are able to simulate a "double-peak"structured solar signal in tropical $\mathrm{O}_{3}$, the simulated upper stratospheric peak is at lower altitudes than SBUV and SAGE observations (e.g. see Fig. 4 in Austin et al., 2008) in almost all cases.

Recently, these differences in the middle atmospheric solar signal have gathered renewed interest with the availability of solar spectral data from the Solar Radiation and Climate Experiment (SORCE), launched in 2003. These SORCE fluxes show significantly different variations compared to the NRLSSI and other irradiance models, as well as to the earlier spectral irradiance measurements (e.g. Ermolli et al., 2013). Using SORCE solar fluxes in a 2-D radiative-dynamicalchemical model, and comparing results with Microwave Limb Sounder (MLS) data, Haigh et al. (2010) argued that the upper stratospheric and lower mesospheric $\mathrm{O}_{3}$ solar signal might be out of phase with TSI during solar cycle 23 . Using the Whole Atmosphere Community Climate Model (WACCM) with SORCE solar fluxes and comparing it with Sounding the Atmosphere using Broadband Emission Radiometry (SABER) data, Merkel et al. (2011) also showed an out-of-phase (larger than $-2 \%$ ) daytime $\mathrm{O}_{3}$ solar signal in the mesosphere and upper stratosphere (above $40 \mathrm{~km}$ ) during the recent solar maximum. Importantly, both Haigh et al. (2010) and Merkel et al. (2011) argued that the recent $\mathrm{O}_{3}$ changes in the upper stratosphere and lower mesosphere cannot be simulated using the NRL-SSI solar fluxes, thereby providing indirect evidence for the fidelity of the SORCE solar fluxes. However, although the WACCM-simulated mesospheric $\mathrm{O}_{3}$ changes with SORCE fluxes showed better agreement with SABER data, the same model run was unable to simulate stratospheric $\mathrm{O}_{3}$ changes (see Fig. $2 \mathrm{~d}$ and $\mathrm{h}$ in Merkel et al., 2011).

In this study we use the SLIMCAT off-line 3-D CTM (Chipperfield, 2006), forced with ECMWF ERA-interim meteorology to simulate recent stratospheric and lower mesospheric $\mathrm{O}_{3}$ changes. Using different solar flux data sets and dynamical conditions, we examine whether the model can reproduce these past $\mathrm{O}_{3}$ changes, and therefore whether the model comparisons can help to establish the accuracy of the solar fluxes used. Section 2 gives a brief description of the various satellite $\mathrm{O}_{3}$ and solar flux data sets used. Section 3 describes the model set-up. Our results are discussed in Sect. 4, and conclusions are summarised in Sect. 5.

\section{Satellite data sets and solar fluxes}

The SABER instrument was launched in December 2001 on board the TIMED (Thermosphere Ionosphere Mesosphere Energetics and Dynamics) satellite. SABER is an infrared radiometer, and $\mathrm{O}_{3}$ profiles are retrieved from the $1.27 \mu \mathrm{m}$ band during the day and from the $9.6 \mu \mathrm{m}$ band for both day and night. SABER therefore provides about 2200 profiles per $24 \mathrm{~h}$ period. Here we use $\mathrm{O}_{3}$ profile data from the $9.6 \mu \mathrm{m}$ band (v1.07) with anomalous $\mathrm{O}_{3}$ profiles removed following Rong et al. (2009). Daytime and night-time measurements are separated using a flag provided in the data files. The vertical resolution of the SABER data is about $2 \mathrm{~km}$ with a useful vertical range between 100 and $0.0002 \mathrm{hPa}(\sim 15-100 \mathrm{~km})$ (Russell III et al., 1999).

MLS was launched onboard the Aura satellite in July 2004. MLS consists of seven radiometers covering spectral regions from $118 \mathrm{GHz}$ to $2.5 \mathrm{THz}$. MLS provides about 3500 profiles per $24 \mathrm{~h}$ period covering both day and night. MLS daytime and night-time profiles are determined by averaging profiles with local solar times between 10-14 and 22-2 (next day), respectively. The vertical resolution of MLS data ranges from $3 \mathrm{~km}$ in the lower stratosphere to about $5.5 \mathrm{~km}$ in the lower mesosphere, with a useful vertical range between 100 and $0.02 \mathrm{hPa}(\sim 16-70 \mathrm{~km})$. MLS has retrieval errors of about $5 \%$ in the middle and upper stratosphere and $10 \%$ in the lower stratosphere (Froidevaux et al., 2008).

SATIRE-S is a semi-empirical model that calculates total and spectral solar irradiance variations (Krivova et al., 2003; Ball et al., 2012). It uses magnetograms and continuum images to identify three components that modulate solar irradiance: faculae, sunspot umbrae and sunspot penumbrae. The rest of the visible solar surface is considered to be the quiet Sun, which is thus the 4 th component of the model. Semiempirical models of the solar atmospheric structure are used to calculate the emergent intensities for each component (Unruh et al., 1999). Weighted by the corresponding area coverage, these intensities are summed up to calculate spectral irradiance at a daily cadence. An Upper Atmosphere Research Satellite/Solar Ultraviolet Spectral Irradiance Monitor (UARS/SUSIM)-based correction is applied to wavelengths below $270 \mathrm{~nm}$ to gain better agreement with observations (Krivova et al., 2006).

The NRL-SSI solar flux model uses the photospheric sunspot index and the $\mathrm{Mg}$ II index to calculate the contribution of sunspots and faculae to irradiance changes, respectively (Lean et al., 1997). To calculate irradiance below $400 \mathrm{~nm}$, a regression with UARS/SOLSTICE (Solar Stellar Irradiance Comparison Experiment) observations is 
performed. This is done on detrended, rotational data to avoid the introduction of long-term instrumental trend.

The SATIRE-S SSI data set ranges from $115 \mathrm{~nm}$ to $0.16 \mathrm{~mm}$ with variable resolution of $1 \mathrm{~nm}$ up to $290 \mathrm{~nm}$, and $2 \mathrm{~nm}$, up to $1000 \mathrm{~nm}$. The NRL-SSI data set is available from $120.5 \mathrm{~nm}$ to $0.1 \mathrm{~mm}$ with $1 \mathrm{~nm}$ resolution up to $750 \mathrm{~nm}$. Both NRL-SSI and SATIRE-S solar flux data show very similar $11 \mathrm{yr}$ solar cycle variability for wavelengths less than $250 \mathrm{~nm}$. Above $250 \mathrm{~nm}$, SATIRE-S displays larger variability, with twice the change in flux compared to NRL-SSI at $300 \mathrm{~nm}$, increasing to a three-fold larger variation at $370 \mathrm{~nm}$. For most wavelengths between 440 and $1250 \mathrm{~nm}$, NRL-SSI is more variable than SATIRE-S.

The SORCE mission is described by Rottman (2005). For the SORCE fluxes used here, we combine data from two of the instruments on board SORCE: the SOLar STellar Irradiance Comparison Experiment (SOLSTICE; McClintock et al. 2005); and the Spectral Irradiance Monitor (SIM; Harder et al. 2009, 2010). We wish to make a direct comparison with Haigh et al. (2010) and thus use the same data set for most of our runs. It is based on SOLSTICE (version 10) below $200 \mathrm{~nm}$ and on SIM intermediate-release version (J. Harder, personal communication, 2010) for wavelengths above $200 \mathrm{~nm}$. We label this data set SORCE_1. The use of SIM data below $310 \mathrm{~nm}$ is no longer recommended, so we also included two test runs using the currently available SORCE data. These data are labelled SORCE_2 and use SOLSTICE (version 12) and SIM (version 17) data for wavelengths below and above $310 \mathrm{~nm}$, respectively.

\section{Model experiments}

SLIMCAT is a 3-D CTM which uses a hybrid $\sigma-\theta$ vertical coordinate system. Model runs were performed at $5.6^{\circ} \times 5.6^{\circ}$ horizontal resolution with 32 vertical levels ranging from the surface to about $64 \mathrm{~km}(\sim 0.1 \mathrm{hPa})$. The model has a fixed lid (no vertical tracer flux) through the top level. The model was forced with 6-hourly (00:00, 06:00, 12:00 and 18:00 UTC) ERA-interim reanalysis data (Dee et al., 2011) for 2001-2010. Vertical velocities are calculated using heating rates and the modelled $\mathrm{O}_{3}$ (Chipperfield, 2006), so a heating-rate-related dynamical response (Oberländer et al., 2012) is incorporated in the simulations. The model has a detailed stratospheric chemistry scheme, and there are 203 spectral intervals in the UV-visible photolysis scheme from 116 to $850 \mathrm{~nm}$ (see WMO, 1985, Tables 7-4). On this wavelength grid model, photolysis rates are calculated using the scheme of Lary and Pyle (1991). Photolysis at the Lyman$\alpha$ wavelength $(121.6 \mathrm{~nm})$ is treated in a separate wavelength bin, and for $\mathrm{O}_{2}$ photolysis the parameterisation of Brasseur and Solomon (1984) is used. $\mathrm{O}_{2}$ photolysis in the SchumannRunge bands (176-192 nm) is treated using the scheme of Minschwaner et al. (1993). In the runs performed here, the model ignored photolysis in the Schumann-Runge contin- uum (i.e. the only wavelength shorter than $172 \mathrm{~nm}$ considered is Lyman- $\alpha$; Brasseur and Solomon 1984, Fig. 4.3). Above the top model level, fixed profiles of $\mathrm{O}_{3}$ and $\mathrm{O}_{2}$ (up to around $90 \mathrm{~km}$ ) are used in the calculation of photolysis rates.

The model heating rates used for the calculation of vertical motion are calculated using a different broadband scheme from the NCAR CCM II (Briegleb, 1992; Chipperfield, 2006). For this the short-wave scheme uses climatological solar fluxes: there is no variation over a solar cycle. In any case the diagnosed vertical motion is largely driven by the specified analysed temperatures. Also as model top level is $\approx 0.1 \mathrm{hPa}$, so above this level the model uses standard atmospheric profiles to determine overhead density (e.g. slant column to determine $\mathrm{O}_{2}$ absorption). There are no upward/downward mass fluxes through the top level, so tracers are not overwritten. At the top level tracers are transported to all the neighbouring grids except upwards. At this level, $\mathrm{O}_{3}$ is very short-lived ( $\sim$ minutes), so this does not affect $\mathrm{O}_{3}$ fields. A detailed sensitivity analysis (not shown) also indicates very little influence from the model upper lid on the distribution of the long-lived gases.

We have performed nine model simulations with different solar flux data sets and dynamical conditions, and these are summarised in Table 1. Run A_NRL used NRLSSI fluxes (similar to run B_Int in Dhomse et al., 2011) while run B_SATIRE used SATIRE-S fluxes for 20012010. Run $C \_F I X$ was similar to run $A \_N R L$ but used the mean NRL-SSI fluxes for 2001-2010. This means that run C_FIX only includes meteorological variability (i.e. no solar flux variations). Due to limited time span of the SORCE data time series, a multi-annual simulation could not be performed with these fluxes. Run D_SORCE2004_l and E_SORCE2007_l are therefore two separate $10 \mathrm{yr}$ simulations with constant SORCE_1 solar fluxes for December 2004 and December 2007, respectively. These are the same fluxes as used in the 2-D model study by Haigh et al. (2010). Two additional simulations with recently updated SORCE_2 solar fluxes are included as run F_SORCE2004_2 and G_SORCE2007_2. Runs $H \_N R L F$ and I_SATIREF are similar to $A \_N R L$ and $B \_S A T I R E$, respectively, but with fixed dynamics (from year 2004); these runs therefore contain solar variability but no meteorological variability.

\section{Results and discussion}

The differences in irradiance from the different solar flux data sets used in our model simulations are shown in Fig. 1. The threshold wavelength $(242 \mathrm{~nm})$ controlling $\mathrm{O}_{3}$ production and destruction is also indicated. As shown in Haigh et al. (2010), at $210 \mathrm{~nm}$ SORCE data show nearly $6 \%$ more UV in December 2004 (solar maximum period) than in December 2007 (solar minimum period). However, NRLSSI and SATIRE-S both show only about a $2 \%$ difference between these two months at this wavelength. Recently, 
Table 1. Solar and dynamical conditions for the model simulations. All the runs are performed for the 2001-2010 time period.

\begin{tabular}{lll}
\hline Run & Solar fluxes & Dynamics \\
\hline A_NRL & NRL-SSI & ERA-interim \\
B_SATIRE & SATIRE & ERA-interim \\
C_FIX & Fixed (mean NRL-SSI, 2001-2010) & ERA-interim \\
D_SORCE2004_1 & SORCE (2004_1) & ERA-interim \\
E_SORCE2007_1 & SORCE (2007_1) & ERA-interim \\
F_SORCE2004_2 & SORCE (2004_2) & ERA-interim \\
G_SORCE2007_2 & SORCE (2007_2) & ERA-interim \\
H_NRLF & NRL-SSI & Fixed (year 2004) \\
I_SATIREF & SATIRE & Fixed (year 2004) \\
\hline
\end{tabular}

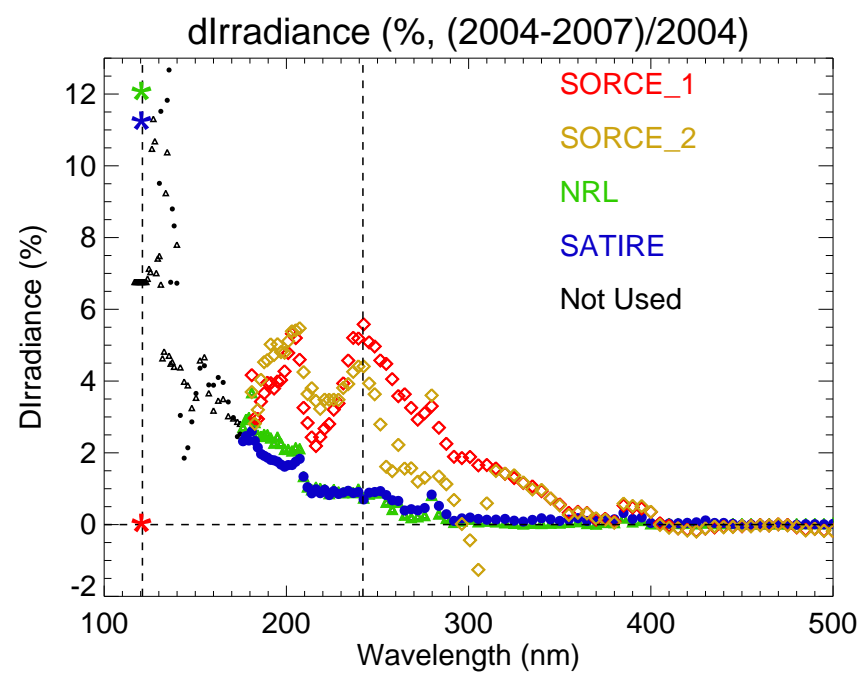

Fig. 1. Relative percentage differences in solar irradiance between 2004 and 2007 ((2004-2007)/2004) for the SORCE_1 and SORCE_2 (red and orange diamonds), NRL-SSI (green triangles) and SATIRE (blue circles) solar flux data sets. The threshold wavelength $(242 \mathrm{~nm})$ controlling $\mathrm{O}_{3}$ production and destruction is indicated with a vertical dashed line. Solar flux changes in the Lyman- $\alpha$ line are indicated with stars $\left(^{*}\right)$ on a vertical dashed line at $121.6 \mathrm{~nm}$. Note that runs with SORCE fluxes do not include Lyman- $\alpha$ changes. Black symbols indicate variations in Schumann-Runge continuum in NRL-SSI and SATIRE data sets but are not included in any of the model simulations.

Woods (2012) and Ermolli et al. (2013) re-evaluated the SORCE data and suggested that the UV variability detected by SORCE might be half of that shown in Fig. 1. DeLand and Cebula (2012) argued that the SORCE_1 flux variations shown in Fig. 1 might be incorrect due to undercorrection of instrument response changes during early on-orbit measurements. This indicates ongoing uncertainty in the accuracy of the SORCE data. Therefore, solar flux differences from recently updated SORCE_2 data are also shown in Fig. 1. We use both versions of the SORCE data (the one used in Haigh et al. (2010) and the updated one) to test the impact on modelled ozone.
There are significant differences between stratospheric and mesospheric $\mathrm{O}_{3}$ chemistry. $\mathrm{O}_{3}$ is dynamically controlled in the lower stratosphere where it is long-lived. In the upper stratosphere, $\mathrm{O}_{3}$ and the odd-oxygen $\left(\mathrm{O}_{\mathrm{x}}\right)$ family have a shorter photochemical lifetime, but $\mathrm{O}_{3}$ is still much more abundant than atomic oxygen, and there is only a weak diurnal cycle. In contrast, there is a strong diurnal cycle in mesospheric $\mathrm{O}_{3}$ via $\mathrm{HO}_{x}$ chemistry (e.g. Marsh et al., 2003) with $\mathrm{O}_{3}$ more abundant at night. Figure 2 shows monthly mean tropical $\left(25^{\circ} \mathrm{S}-25^{\circ} \mathrm{N}\right)$ daytime and night-time $\mathrm{O}_{3}$ profiles from SABER, MLS and run $A_{-} N R L$. Overall, there is good agreement between modelled and observed $\mathrm{O}_{3}$ during both December 2004 and December 2007. However, the peak in modelled $\mathrm{O}_{3}$ seems to be at a lower altitude, and upper stratospheric $\mathrm{O}_{3}$ values are slightly smaller than those from $\mathrm{SABER}$ and MLS. Daytime $\mathrm{O}_{3}$ values are in good agreement in the lower mesosphere, but above $55 \mathrm{~km}$ modelled nighttime $\mathrm{O}_{3}$ mixing ratios are less than observed by SABER or MLS. The estimated amplitude of the $\mathrm{O}_{3}$ diurnal cycle (daytime mean minus night-time mean) is also shown in Fig. 2. As expected, there are small differences in the stratosphere (up to $0.5 \mathrm{ppm}$, or $5 \%$ ), with the daytime (13:30 UTC) values slightly larger. This is due to differences in the production and destruction of $\mathrm{O}_{\mathrm{x}}$ during the day with the production more strongly peaked in the middle of the day. In the mesosphere the diurnal cycle is larger with nighttime values greater than daytime. This reflects conversion of $\mathrm{O}$ to $\mathrm{O}_{3}$ at night. However, the amplitude of the diurnal cycle in modelled $\mathrm{O}_{3}$ in the mesosphere above $55 \mathrm{~km}$ seems to be slightly lower than those observed in SABER and MLS data. Some of the model-MLS-SABER differences can be explained by the sampling time. As MLS equatorial crossing time is 01:30 and 13:30 UTC, both model and MLS profiles are shown for identical local time. However, due to the circular orbit of the TIMED satellite, the equatorial crossing time for SABER varies from dawn to dusk in three months. 


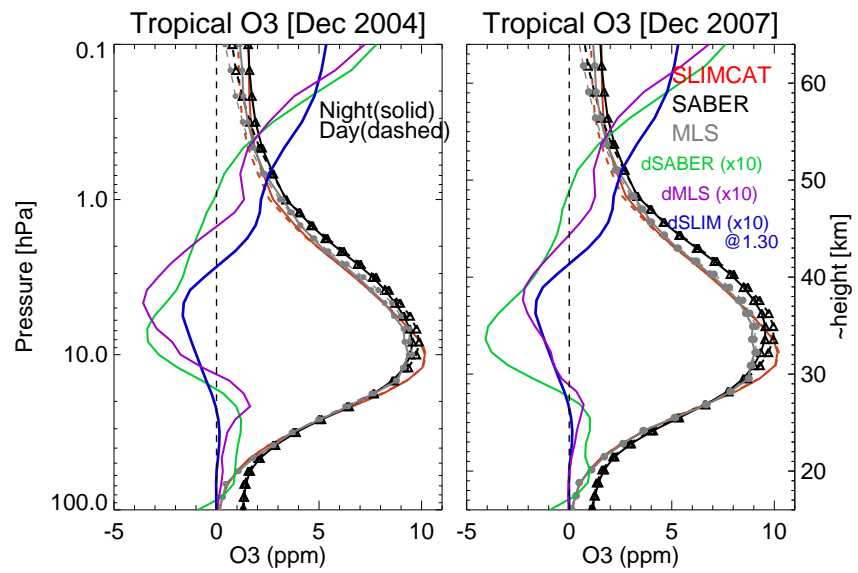

Fig. 2. Monthly mean tropical $\left(25^{\circ} \mathrm{S}-25^{\circ} \mathrm{N}\right) \mathrm{O}_{3}$ profiles for December 2004 and December 2007 from SABER data (black), MLS data (grey) and SLIMCAT run $A \_N R L$ (orange). Solid and dashed lines represent night-time and daytime profiles, respectively. Also shown is the $\mathrm{O}_{3}$ diurnal variation (night-day) for SABER (green), MLS (violet) and SLIMCAT (light blue). The SLIMCAT differences are shown for 01:30 UTC and 13:30 UTC. For clarity, the diurnal variations have been multiplied by 10 .

Figure 3 shows tropical $\left(25^{\circ} \mathrm{S}-25^{\circ} \mathrm{N}\right) \mathrm{O}_{3}$ anomalies at $0.3,3$ and $30 \mathrm{hPa}$ from model runs $A \_N R L, B \_S A T I R E$, and C_FIX (2001-2010) along with SABER (2002-2010) and MLS (2004-2010) observations. Excellent agreement among satellite and modelled $\mathrm{O}_{3}$ anomalies is observed at the $3 \mathrm{lev}-$ els with typical differences between them less than $1 \%$. This is not surprising as middle-lower stratospheric $\mathrm{O}_{3}$ is dynamically controlled, and our simulations use realistic dynamics (including the Quasi-Biennial Oscillation or QBO). Overall, the modelled $\mathrm{O}_{3}$ anomalies are better correlated with MLS than SABER. For example, at $30 \mathrm{hPa}$ and $3 \mathrm{hPa}$, the MLSmodel correlation is 0.9 while for MLS-SABER it is 0.8 , highlighting the differences in the observational data sets. The MLS-SABER differences are largest in 2005 and 2008. In general, prior to 2005, SABER $\mathrm{O}_{3}$ anomalies are slightly smaller $(<0.5 \%)$ than MLS and SLIMCAT at all levels, and they become slightly larger afterwards.

The good correlation between modelled and satellite $\mathrm{O}_{3}$ anomalies provides confidence in the middle and upper stratospheric $\mathrm{O}_{3}$ changes during this period. However, the weaker correlations in the observational data sets in the lower mesosphere $(0.3 \mathrm{hPa})$ (e.g. Mieruch et al., 2012) suggest that $\mathrm{O}_{3}$ changes in this region must be carefully interpreted. Some model-SABER differences during the first few months of the SABER period might be due to reported ice build-up in the SABER detector during this time (Rong et al., 2009).

Zonal mean $\mathrm{O}_{3}$ mixing ratios for December 2004 from SLIMCAT (runs A_NRL, C_FIX, D_SORCE2004_1, and F_SORCE2004_2), SABER and MLS are shown in Fig. 4. Results from run B_SATIRE are not shown as they are similar to run $A_{-} N R L$. Although there is generally excellent agree-

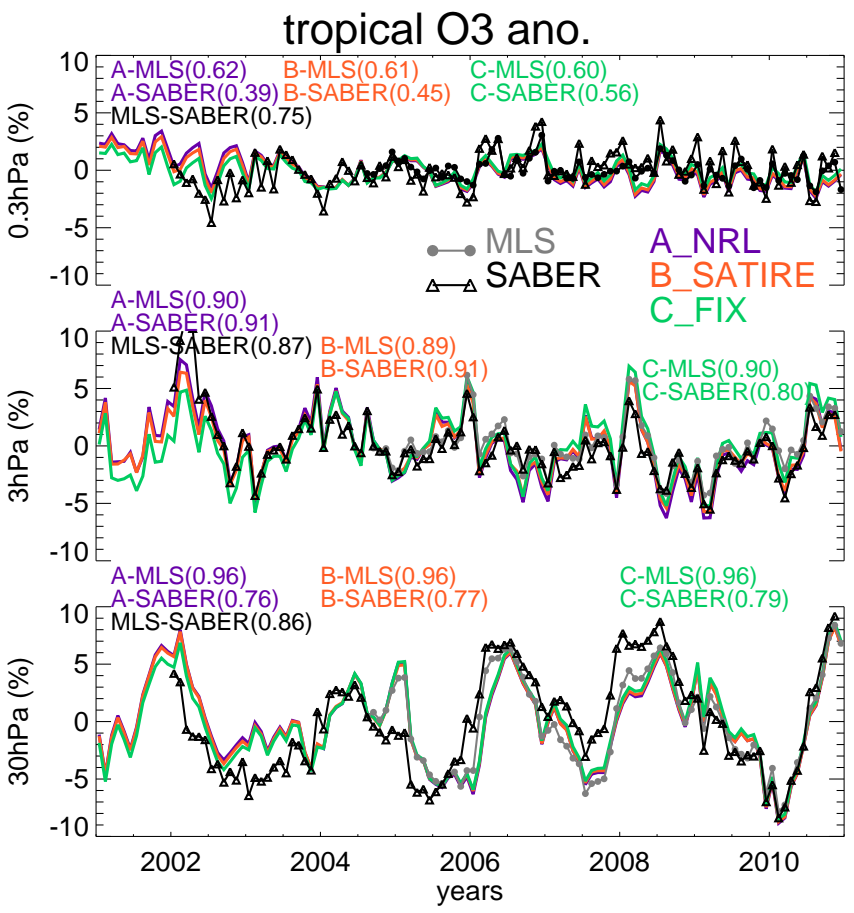

Fig. 3. Tropical $\left(25^{\circ} \mathrm{S}-25^{\circ} \mathrm{N}\right) \mathrm{O}_{3}$ anomalies (\%) from 3 model simulations (run $A \_N R L$ - violet, run $B \_S A T I R E$ - orange, run $C \_F I X$ green) and satellite data (MLS (2004-2010) - filled circles, SABER (2002-2010) - triangles) at $30 \mathrm{hPa}$ (bottom), $3 \mathrm{hPa}$ (middle) and $0.3 \mathrm{hPa}$ (top). Monthly mean anomalies are calculated by subtracting climatological monthly mean values from each monthly mean. The climatological monthly means are over different time periods for individual satellite and model time series. The rank correlation between different $\mathrm{O}_{3}$ anomalies is also given.

ment in the $\mathrm{O}_{3}$ distribution, some differences in modelled and satellite $\mathrm{O}_{3}$ in the tropical stratosphere are visible. In the middle stratosphere (near $10 \mathrm{hPa}$ ) MLS values are slightly smaller than SABER and SLIMCAT. In the lower stratosphere (below $50 \mathrm{hPa}$ ) and the lower mesosphere (above $1 \mathrm{hPa}$ ), SABER mixing ratios are larger than SLIMCAT and MLS.

Figure 4 also shows the relative $\mathrm{O}_{3}$ differences between December 2004 and December 2007. Haigh et al. (2010) showed differences for daytime $\mathrm{O}_{3}$ only (their Fig. 2), whilst our differences shown in Fig. 4 include both daytime and night-time $\mathrm{O}_{3}$. Also, Haigh et al. (2010) used a coupled dynamical-chemical 2-D model, so a direct comparison with their results cannot be performed. However, some differences in $\mathrm{O}_{3}$ between the 2-D model and SLIMCAT (runs $A \_N R L$ as well as D_SORCE2004_1 minus E_SORCE2007_l) are noticeable. As in Haigh et al. (2010) (with SORCE_1 fluxes), a $2-4 \% \quad \mathrm{O}_{3}$ increase in the tropical middle stratosphere is clearly visible in all SLIMCAT simulations, confirming that the middle stratospheric enhancement can be simulated with NRL-SSI (or SATIRE), fixed and SORCE solar fluxes as the model uses realistic dynamics. However, 

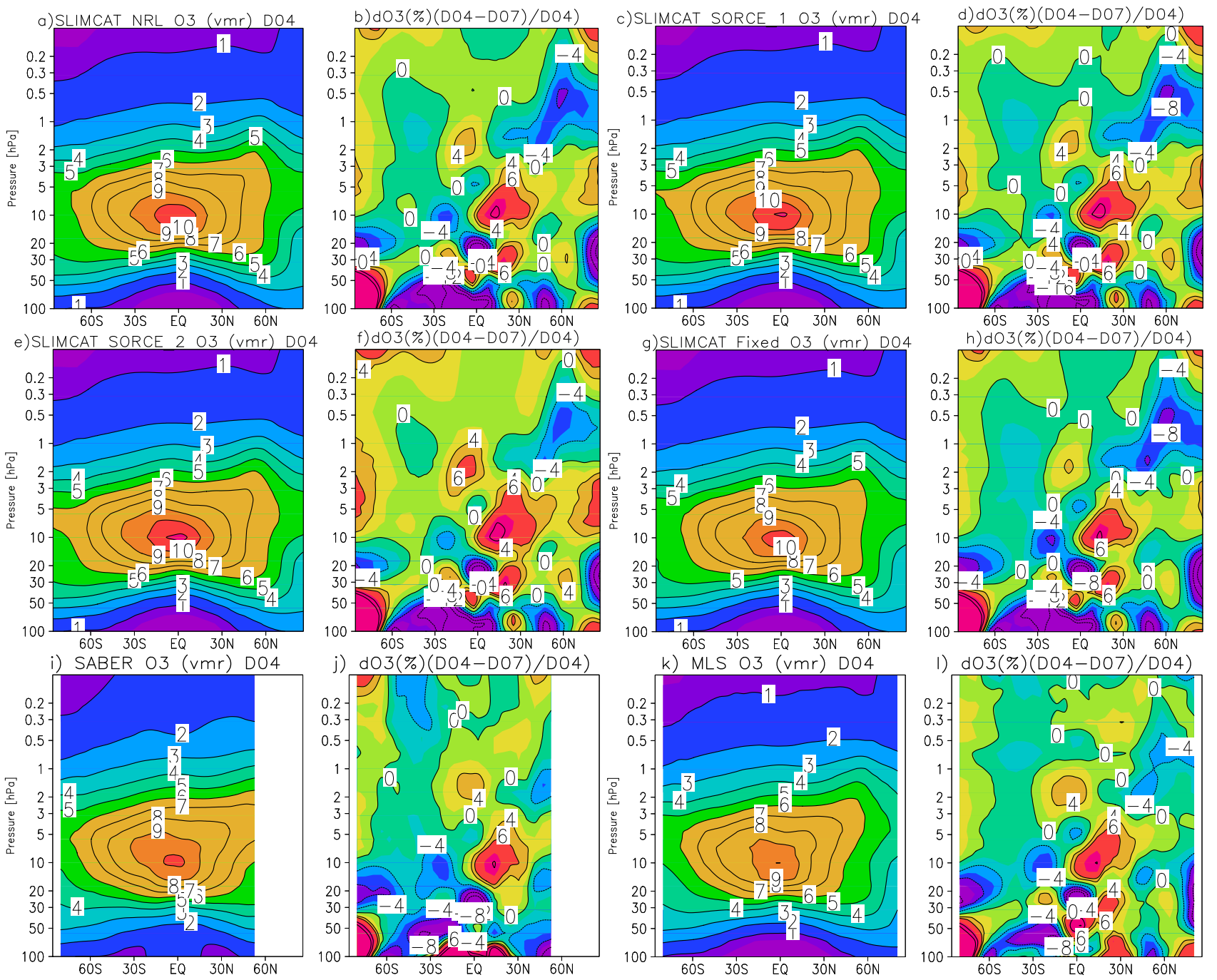

Fig. 4. Zonal mean monthly mean $\mathrm{O}_{3}$ mixing ratio (ppmv) from SLIMCAT runs A_NRL, D_SORCE2004_1, F_SORCE2004_1, C_FIX (a, c, e and $\mathbf{g}$ ) and SABER and MLS (i and $\mathbf{k}$ ) for December 2004. The ozone differences (\%) between December 2004 and December 2007 for the corresponding data sets are also shown $(\mathbf{b}, \mathbf{d}, \mathbf{f}, \mathbf{h}, \mathbf{j}, \mathbf{l})$.

significant $\mathrm{O}_{3}$ reductions in the tropical upper stratosphere (above $1 \mathrm{hPa}$ ) produced in the 2-D model with SORCE solar fluxes are not visible in MLS, SABER or any SLIMCAT simulation. Note that both the runs with SORCE fluxes (runs D_SORCE2004_I and F_SORCE2004_2) have larger $\mathrm{O}_{3}$ mixing ratios than run $A_{-} N R L$ in December 2004. This is due to absolute differences between NRL-SSI and SORCE fluxes; the exact cause of this difference in solar fluxes is beyond the scope of this study.

Another interesting feature in Fig. 4 is the $10 \%$ increase in $\mathrm{O}_{3}$ in the range of $0-30^{\circ} \mathrm{N}$ and $15-5 \mathrm{hPa}$, which is distinctly noticeable in the observations and is well captured by the model. The model also captures the $\sim 10 \%$ less $\mathrm{O}_{3}$ between $5^{\circ} \mathrm{S}-5^{\circ} \mathrm{N}$ near $30 \mathrm{hPa}, 20-40^{\circ} \mathrm{S}$ near $70 \mathrm{hPa}$, and $70-90^{\circ} \mathrm{S}$ near $20 \mathrm{hPa}$. However, there are differences in the SABER and MLS observations. Enhanced $\mathrm{O}_{3}$ in the tropical lower stratosphere near $50 \mathrm{hPa}$ is seen by MLS and the model, but does not appear in the SABER data. SABER also observed nearly $2 \%$ less $\mathrm{O}_{3}$ in the Southern Hemisphere (SH) midlatitude upper stratosphere (above $0.3 \mathrm{hPa}$ ), which is not seen by MLS or reproduced by the model.

To analyse the effect of the diurnal cycle and for better comparison with Haigh et al. (2010), annual mean daytime and night-time $\mathrm{O}_{3}$ differences between 2004 and 2007 with SORCE fluxes (runs D_SORCE2004_l minus E_SORCE2007_1) are shown in Fig. 5. Although the most recent SORCE solar fluxes are different to those used by Haigh et al. (2010), this did not lead to any major change to the mean $\mathrm{O}_{3}$ distributions (runs F_SORCE2004_2 and G_SORCE2007_2), so they are not shown here. A middle stratospheric $\mathrm{O}_{3}$ enhancement of nearly $+6 \%$ during 2004 (near $5 \mathrm{hPa}$ ) is clearly visible in 

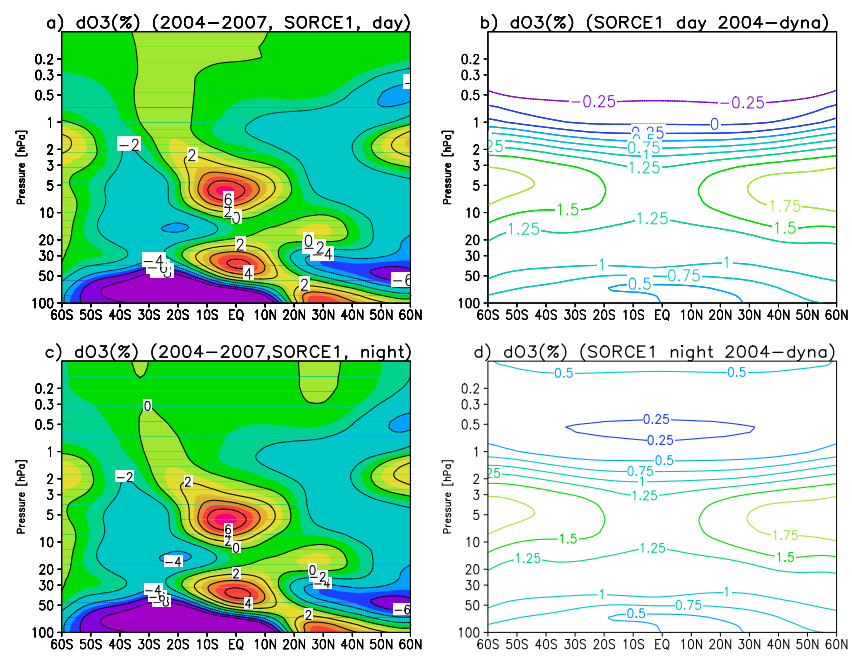

Fig. 5. (a) Differences in annual mean zonal mean $\mathrm{O}_{3}$ between 2004 and 2007 for D_SORCE2004_1 and E_SORCE2007_1 in daytime (i.e. $\mathrm{O}_{3}$ change due to both solar flux and dynamical variability). (b) Similar to (a) but for fixed meteorological forcing (year 2004, i.e. $\mathrm{O}_{3}$ changes only due to solar flux variability). (c) and (d) are similar to (a) and (b), respectively but for night-time $\mathrm{O}_{3}$.

both daytime and night-time $\mathrm{O}_{3}$ (see also Fig. 4h). Hence most of these $\mathrm{O}_{3}$ changes must be due to dynamical changes. Interestingly these positive $\mathrm{O}_{3}$ differences in the tropics are much larger than the 2-D model. However, at mid-high latitudes SLIMCAT shows negative differences (i.e. more $\mathrm{O}_{3}$ in 2007) while the 2-D model showed nearly uniform positive differences throughout the stratosphere. These negative $\mathrm{O}_{3}$ differences are distinctly visible between 40 and $60^{\circ} \mathrm{N}$.

In the upper stratosphere and lower mesosphere, SLIMCAT does not show any significant $\mathrm{O}_{3}$ differences. However, in a fixed (or identical) dynamics simulation (with different SORCE fluxes), they are slightly negative during the day but become positive at night. For the mean solar signal in $\mathrm{O}_{3}$ in the lower mesosphere, these effects seem to cancel out. This is in disagreement with Merkel et al. (2011), who argued for an insignificant solar signal in night-time $\mathrm{O}_{3}$, and thus an average $\mathrm{O}_{3}$ solar signal remains negative. Additionally, with updated SORCE solar fluxes, SLIMCAT simulates almost $3 \%$ more $\mathrm{O}_{3}$ in the middle stratosphere between December 2004 and December 2007 compared to $1.5 \%$ using older SORCE fluxes (not shown).

Figure 6 shows daytime and night-time $\mathrm{O}_{3}$ differences between 2003-2004 and 2008-2009 from model runs $A \_N R L$, B_SATIRE, C_FIX and SABER. We have selected the pairs of years as active and quiet solar periods in order to make a direct comparison with the results from Merkel et al. (2011). Again, the $\mathrm{O}_{3}$ difference patterns between observational and modelled data are nearly similar. The SABER data and all three model simulations show 3-6\% more $\mathrm{O}_{3}$ in the tropical middle stratosphere during 2003-2004 compared to 2008-2009. Negative differences in the lower strato-
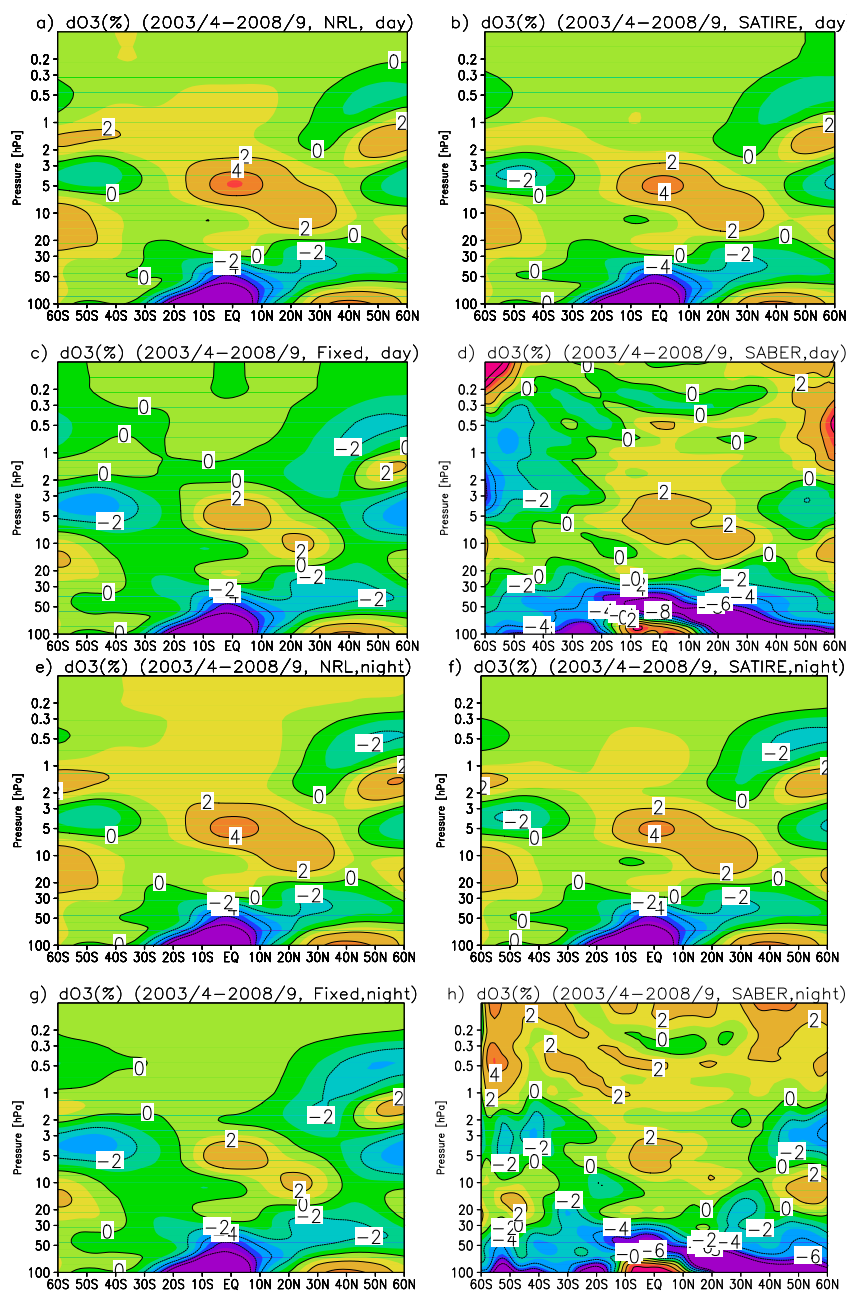

Fig. 6. Daytime (a-d) and night-time (e-h) biannual mean zonal mean $\mathrm{O}_{3}$ differences (\%) between 2003/2004 and 2008/2009 for (a and e) SLIMCAT run $A \_N R L$, (b and f) SLIMCAT run B_SATIRE, (c and $\mathbf{g}$ ) SLIMCAT run $C \_F I X$ and (d and h) SABER data.

sphere (near $50 \mathrm{hPa}$ ) are also in agreement between the data and model runs. The simulations show negligible $(<1 \%) \mathrm{O}_{3}$ differences in the upper stratosphere and lower mesosphere. SABER also shows nearly $0.5 \%$ negative $\mathrm{O}_{3}$ anomalies in a narrow region near $0.3 \mathrm{hPa}$ in both daytime and nighttime data. $\mathrm{SH}$ mid-latitude $\mathrm{SABER}$-observed $\mathrm{O}_{3}$ changes are better captured in run $B \_S A T I R E$ than run $A \_N R L$, whereas $\mathrm{NH}$ mid-latitude changes are in better agreement with run $A \_N R L$. However, due to the limited spatial coverage of SABER measurements, mid-latitude $\mathrm{O}_{3}$ differences are not discussed here.

As expected, our analysis of SABER data shown in Fig. 6 is consistent with the active (2003/2004) and quiet (2008/2009) period $\mathrm{O}_{3}$ differences shown in Figure 2 of Merkel et al. (2011). However, the SLIMCAT O $\mathrm{O}_{3}$ differences do not agree with WACCM differences using NRL-SSI in that study. The tropical mid-stratospheric $\mathrm{O}_{3}$ anomalies 

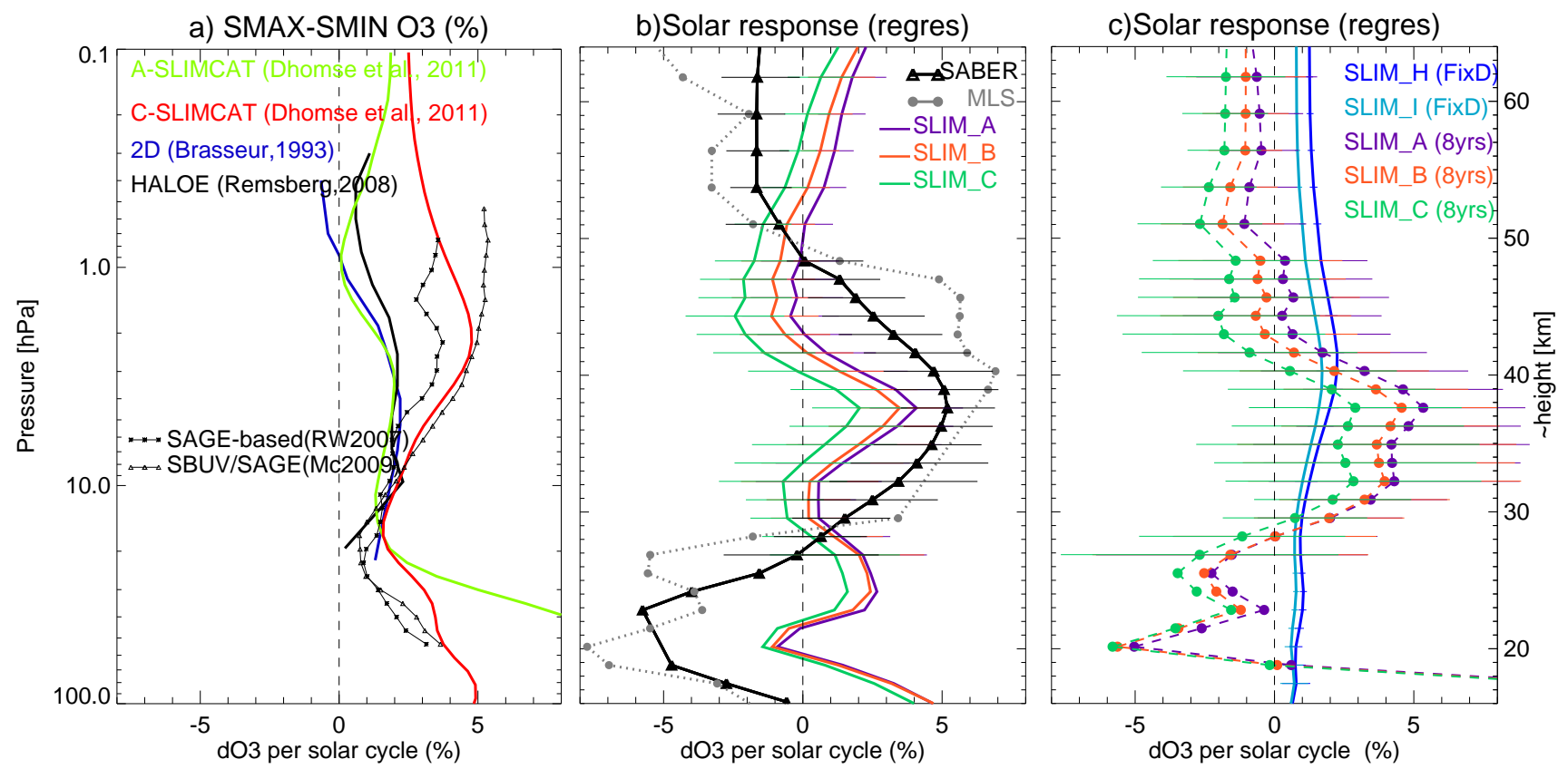

Fig. 7. (a) Tropical solar signal $\left(25^{\circ} \mathrm{S}-25^{\circ} \mathrm{N}\right)$ per solar cycle from SLIMCAT simulations for 1979-2010 with ERA-40 and fixed dynamics (Dhomse et al., 2011, green and red lines), HALOE (1992-2005, Remsberg, 2008, black line) and a 2-D model (Brasseur, 1993, blue line). The estimated solar signals using SBUV/SAGE data (McLinden et al., 2009, triangles), SAGE-based data (Randel and Wu, 2007, stars) and a 3-D model (light-green line) by Dhomse et al. (2011) for 1979-2005 are also shown. (b) Estimated solar signal using multivariate regression model for modelled (2001-2010, 120 months), SABER (2002-2010, 108 months) and MLS (2004-2010, 77 months) $\mathrm{O}_{3}$ data sets. Estimated errors $(1 \sigma)$ for solar coefficients are shown with coloured horizontal lines. The large error bars $( \pm 10 \%)$ at all levels for MLS data and in the lower stratosphere for SABER and model data are not shown. (c) The coloured dashed lines with filled circles show the solar signal from runs $A \_N R L$ and $B \_S A T I R E$ if only 8 yr (2003-2010) of model data are used. The estimated solar signals from the runs (fixed dynamics) H_NRLF and I_SATIREF are shown with dark and light blue lines, respectively.

with NRL-SSI or SORCE solar fluxes shown by Merkel et al. (2011) are less than $1 \%$, whereas our simulations and SABER show around $2-4 \% \mathrm{O}_{3}$ differences. A good agreement between SLIMCAT and observations is expected as we use analysed winds and temperatures, whereas WACCM is a coupled model and therefore can calculate the coupled solar response. So difference reported in Merkel et al. (2011) might be coupled dynamical response. However, this again highlights that robust positive $\mathrm{O}_{3}$ anomalies observed in SABER data can be reproduced in SLIMCAT with either NRL-SSI or SATIRE solar fluxes. Negligible upper stratospheric lower mesospheric $\mathrm{O}_{3}$ changes with NRL-SSI are in good agreement with their simulations (see Figure 2a and e in Merkel et al., 2011).

Figure 7a shows the solar signals from some earlier studies (e.g. HALOE (Remsberg, 2008), a 2-D model (Brasseur, 1993) and a 3-D model (Dhomse et al., 2011)). A midstratospheric solar signal in earlier SLIMCAT simulations with NRL-SSI fluxes is consistent with other modelling studies (e.g. Austin et al., 2008, see Figure 4). Figure 7b shows the estimated solar signal in tropical $\left(25^{\circ} \mathrm{S}-25^{\circ} \mathrm{N}\right) \mathrm{O}_{3}$ using modelled and observed $\mathrm{O}_{3}$ anomalies from this study. The regression model used here is similar to the one used in
Dhomse et al. (2011) containing linear trend, QBO and solar ( $F_{10.7}$ flux) terms (see also Dhomse et al., 2006). Overall the solar signals from runs $A \_N R L$ and $B \_S A T I R E$ are in good agreement with SABER (and HALOE) data. However, due to the short time span of available MLS data (77 months), the estimated errors in the MLS solar signal are much larger. A robust positive solar signal in the middle stratosphere is clearly visible in the model simulations as well as SABER and MLS data sets.

There are some differences in the solar signals estimated from modelled and observed $\mathrm{O}_{3}$ in Fig. 7b, but they are statistically insignificant. For example, the secondary solar signal maxima in the tropical lower stratospheric $\mathrm{O}_{3}$ observed in SBUV, SAGE and SLIMCAT are not visible in SABER and MLS data. In the upper stratosphere and lower mesosphere, modelled $\mathrm{O}_{3}$ shows a positive $(\sim 1 \%)$ solar signal, whereas in the observational data it is negative $(\sim-1 \%)$. Some of these differences might be due to ice contamination in the SABER detector as discussed earlier.

In Fig. 7c, the regression is applied for the 2003-2010 time period. Both runs $A \_N R L$ and $B \_S A T I R E$ show a negative solar signal in the lower mesosphere. This clearly highlights the importance of the time period used to quantify the $\mathrm{O}_{3}$ solar 
signal. Figure 7c also shows the "chemical-only" solar response for the 2001-2010 period from fixed dynamical simulations (runs $H \_N R L F$ and I_SATIREF). Again, the solar signal from these simulations shows quite good agreement with the solar signal from SAGE and SBUV data (Soukharev and Hood, 2006). However, its magnitude is less than that for the fixed dynamical simulations presented in Dhomse et al. (2011). This is in line with our expectations, as the 2001-2010 time period only partially covers the solar cycle.

\section{Conclusions}

When using either NRL-SSI or SATIRE-S solar fluxes, and ECMWF meteorology, simulated $\mathrm{O}_{3}$ from our 3-D CTM shows excellent agreement with satellite observations for 2001-2010. The model is also able to reproduce changes over the recent 2004-2007 time period, which has previously been used to support the different solar flux variability measured by SORCE. Therefore, our model runs do not provide any indirect support for the accuracy of the SORCE fluxes; rather they argue that the previously accepted NRL-SSI or SATIRE-S fluxes are able to reproduce recent observed $\mathrm{O}_{3}$ changes.

The good agreement between our model and observations is partly due to variability imposed by the ECMWF analyses, which is therefore dynamical in origin. However, since 2001, there have been step-wise changes in stratospheric circulation (e.g. Dhomse et al., 2008), and there was a major sudden stratospheric warming in the SH in September 2002 (e.g. Weber et al., 2003). It will require further research using a coupled chemistry-climate model to see if these anomalous changes in stratospheric circulation are indeed solar-induced or due to internal atmospheric variability or anthropogenic origin.

Our modelled $\mathrm{O}_{3}$ solar signal in the middle and upper stratosphere during the 2001-2010 time period is different to that deduced from SBUV or SAGE data (1979-2003), but only slightly different (similar structure but larger in magnitude) to HALOE (1992-2005). However, there are some uncertainties in the SBUV (e.g. poor vertical resolution) and SAGE (e.g. limited temporal sampling, Twomey-Chahine inversion near $50 \mathrm{~km}$ ) data sets (e.g. Terao and Logan, 2007; Wang et al., 2011). A re-evaluation of SBUV and SAGE data is needed to confirm if the solar signal in stratospheric $\mathrm{O}_{3}$ during the recent solar cycle is indeed out of phase with TSI changes. Overall, our simulations suggest that an out-ofphase solar signal in the lower mesospheric $\mathrm{O}_{3}$ during recent solar cycle cannot be used to distinguish between the various solar flux data sets due to large uncertainties and the short time span of the observations.

Acknowledgements. We thank NASA for the MLS and SABER $\mathrm{O}_{3}$ data sets. We also acknowledge use of the ECMWF data, which was obtained via the BADC. This work was supported by the
NERC SOLCLI project, STFC, NCAS and NCEO. The National Center for Atmospheric Research is sponsored by the National Science Foundation.

Edited by: Q. Errer

\section{References}

Austin, J., Tourpali, K., Rozanov, E., Akiyoshi, H., Bekki, S., Bodeker, G., Bruehl, C., Butchart, N., Chipperfield, M., Deushi, M., Fomichev, V. I., Giorgetta, M. A., Gray, L., Kodera, K., Lott, F., Manzini, E., Marsh, D., Matthes, K., Nagashima, T., Shibata, K., Stolarski, R. S., Struthers, G. H., and Tian, W.: Coupled chemistry climate model simulations of the solar cycle in ozone and temperature, J. Geophys. Res., 113, D11306, doi:10.1029/2007JD009391, 2008.

Ball, W. T., Unruh, Y., Krivova, N. A., Solanki, S., Wenzler, T., Mortlock, D. J., and Jaffe, A. H.: Reconstruction of total solar irradiance 1974-2009, Astron. Astrophys., 541, A37, doi:10.1051/0004-6361/201118702, 2012.

Brasseur, G.: The response of the middle atmosphere to long-term and short-term solar variability: A two-dimensional model, J. Geophys. Res., 98, 23079-23090, 1993.

Brasseur, G. and Solomon, S.: Aeronomy of the middle atmosphere, D. Reidel Publishing Company, 1984.

Briegleb, B. P.: Delta-Eddington approximation for solar radiation in the NCAR Community Climate Model, J. Geophys. Res., 97, 7603-7612, 1992.

Chipperfield, M. P.: New Version of the TOMCAT/SLIMCAT OffLine Chemical Transport Model: Intercomparison of Stratospheric Tracer Experiments, Q. J. Roy. Meteor. Soc., 132, 11791203, 2006.

Dee, D. P., Uppala, S. M., Simmons, A. J., Berrisford, P., Poli, P., Kobayashi, S., Andrae, U., Balmaseda, M. A., Balsamo, G., Bauer, P., Bechtold, P., Beljaars, A. C. M., van de Berg, L., Bidlot, J., Bormann, N., Delsol, C., Dragani, R., Fuentes, M., Geer, A. J., Haimberger, L., Healy, S., Hersbach, H., Holm, E. V., Isaksen, L., Kayllberg, P., Koehler, M., Matricardi, M., McNally, A. P., Monge-Sanz, B. M., Morcrette, J.-J., Peubey, C., de Rosnay, P., Tavolato, C., Thépaut, J.-N., and Vitart, F.: The ERAInterim reanalysis: Configuration and performance of the data assimilation system, Q. J. Roy. Meteor. Soc., 133, 1972-1990, 2011.

DeLand, M. T. and Cebula, R. P.: Solar UV variations during the decline of Cycle 23, J. Atmos. Sol.-Terr. Phys., 77, 225-234, 2012.

Dhomse, S., Weber, M., Wohltmann, I., Rex, M., and Burrows, J. P.: On the possible causes of recent increases in northern hemispheric total ozone from a statistical analysis of satellite data from 1979 to 2003, Atmos. Chem. Phys., 6, 1165-1180, doi:10.5194/acp-6-1165-2006, 2006.

Dhomse, S., Weber, M., and Burrows, J.: The relationship between tropospheric wave forcing and tropical lower stratospheric water vapor, Atmos. Chem. Phys., 8, 471-480, doi:10.5194/acp-8-4712008, 2008.

Dhomse, S., Chipperfield, M. P., Feng, W., and Haigh, J. D.: Solar response in tropical stratospheric ozone: a 3-D chemical transport model study using ERA reanalyses, Atmos. Chem. Phys., 11, 12773-12786, doi:10.5194/acp-11-12773-2011, 2011. 
Ermolli, I., Matthes, K., Dudok de Wit, T., Krivova, N. A., Tourpali, K., Weber, M., Unruh, Y. C., Gray, L., Langematz, U., Pilewskie, P., Rozanov, E., Schmutz, W., Shapiro, A., Solanki, S. K., and Woods, T. N.: Recent variability of the solar spectral irradiance and its impact on climate modelling, Atmos. Chem. Phys., 13, 3945-3977, doi:10.5194/acp-13-3945-2013, 2013.

Froidevaux, L., Jiang, Y. B., Lambert, A., Livesey, N. J., Read, W. G., Waters, J. W., Browell, E. V., Hair, J. W., Avery, M. A., Mcgee, T. J., Twigg, L. W., Sumnicht, G. K., Jucks, K. W., Margitan, J. J., Sen, B., Stachnik, R. A., Toon, G. C., Bernath, P. F., Boone, C. D., Walker, K. A., Filipiak, M. J., Harwood, R. S., Fuller, R. A., Manney, G. L., Schwartz, M. J., Daffer, W. H., Drouin, B. J., Cofield, R. E., Cuddy, D. T., Jarnot, R. F., Knosp, B. W., Perun, V. S., Snyder, W. V., Stek, P. C., Thurstans, R. P., and Wagner, P. A.: Validation of Aura Microwave Limb Sounder stratospheric ozone measurements, J. Geophys. Res., 113, D15S20, doi:10.1029/2007JD008771, 2008.

Gray, L., Beer, J., M., G., Haigh, J., Lockwood, M., Matthes, K., Cubasch, U., Fleitmann, D., Harrison, G., Hood, L., Luterbacher, J., Meehl, G., Shindell, D., van Geel, B., and White, W.: Solar Influences on Climate, Rev. Geophys., 48, RG4001, doi:10.1029/2009RG000282, 2010.

Haigh, J. D., Winning, A. R., Toumi, R., and Harder, J. W.: An influence of solar spectral variations on radiative forcing of climate, Nature, 467, 696-699, 2010.

Harder, J., Thuillier, G., Richard, E., Brown, S., Lykke, K., Snow, M., McClintock, W., Fontenla, J., Woods, T., and Pilewskie, P.: The SORCE SIM solar spectrum: Comparison with recent observations, Sol. Phys., 263, 3-24, 2010.

Harder, J. W., Fontenla, J. M., Pilewskie, P., Richard, E. C., and Woods, T. N.: Trends in solar spectral irradiance variability in the visible and infrared, Geophys. Res. Lett., 36, L07801, doi:10.1029/2008GL036797, 2009.

Krivova, N., Solanki, S., Fligge, M., and Unruh, Y. C.: Reconstruction of solar irradiance variations in cycle 23: Is solar surface magnetism the cause?, Astron. Astrophys., 399, 1-4, 2003.

Krivova, N., Solanki, S., and Floyd, L.: Reconstruction of solar UV irradiance in cycle 23, Astron. Astrophys., 452, 631-639, doi:10.1051/0004-6361:20064809, 2006.

Lary, D. and Pyle, J.: Diffuse radiation, twilight, and photochemistry-I, J. Atmos. Chem., 13, 373-392, 1991.

Lean, J. L., Rottman, G. J., Kyle, H. L., Woods, T. N., Hickey, J. R., and Puga, L. C.: Detection and parameterization of variations in solar mid- and near-ultraviolet radiation (200-400 nm), J. Geophys. Res, 102, 29939-29956, 1997.

Marsh, D., Smith, A., and Noble, E.: Mesospheric ozone response to changes in water vapor, J. Geophys. Res., 108, 4109, doi:10.1029/2002JD002705, 2003.

McClintock, W. E., Rottman, G. J., and Woods, T. N.: Solar-stellar irradiance comparison experiment II (SOLSTICE II): instrument concept and design, in: The Solar Radiation and Climate Experiment (SORCE), 225-258, Springer, 2005.

McLinden, C. A., Tegtmeier, S., and Fioletov, V.: Technical Note: A SAGE-corrected SBUV zonal-mean ozone data set, Atmos. Chem. Phys., 9, 7963-7972, doi:10.5194/acp-9-7963-2009, 2009

Merkel, A. W., Harder, J. W., Marsh, D. R., Smith, A. K., Fontenla, J. M., and Woods, T.: The impact of solar spectral irradiance vari- ability on middle atmospheric ozone, Geophys. Res. Lett., 38, L13802, doi:10.1029/2011GL047561, 2011.

Mieruch, S., Weber, M., von Savigny, C., Rozanov, A., Bovensmann, H., Burrows, J. P., Bernath, P. F., Boone, C. D., Froidevaux, L., Gordley, L. L., Mlynczak, M. G., Russell III, J. M., Thomason, L. W., Walker, K. A., and Zawodny, J. M.: Global and long-term comparison of SCIAMACHY limb ozone profiles with correlative satellite data (2002-2008), Atmos. Meas. Tech., 5, 771-788, doi:10.5194/amt-5-771-2012, 2012.

Minschwaner, K., Salawitch, R., and McElroy, M.: Absorption of solar radiation by $\mathrm{O}_{2}$ : Implications for $\mathrm{O}_{3}$ and lifetimes of $\mathrm{N}_{2} \mathrm{O}$, $\mathrm{CFCl}_{3}$, and $\mathrm{CF}_{2} \mathrm{Cl}_{2}$, J. Geophys. Res., 98, 10543-10561, 1993.

Oberländer, S., Langematz, U., Matthes, K., Kunze, M., Kubin, A., Harder, J., Krivova, N. A., Solanki, S. K., Pagaran, J., and Weber, M.: The influence of spectral solar irradiance data on stratospheric heating rates during the 11 year solar cycle, Geophys. Res. Lett., 39, L01801, doi:10.1029/2011GL049539, 2012.

Randel, W. J. and Wu, F.: A stratospheric ozone profile data set for 1979-2005: Variability, trends, and comparisons with column ozone data, J. Geophys. Res., 112, D06313, doi:10.1029/2006JD007339, 2007.

Remsberg, E. E.: On the response of Halogen Occultation Experiment (HALOE) stratospheric ozone and temperature to the 11-year solar cycle forcing, J. Geophys. Res., 113, D22304, doi:10.1029/2008JD010189, 2008.

Rong, P. P., Russell III, J. M., Mlynczak, M. G., Remsberg, E. E., Marshall, B. T., Gordley, L. L., and López-Puertas, M.: Validation of Thermosphere Ionosphere Mesosphere Energetics and Dynamics/Sounding of the Atmosphere using Broadband Emission Radiometry (TIMED/SABER) v1.07 ozone at $9.6 \mu \mathrm{m}$ in altitude range 15-70 km, J. Geophys. Res., 114, D04306, doi:10.1029/2008JD010073, 2009.

Rottman, G.: The SORCE mission, in: The Solar Radiation and Climate Experiment (SORCE), 7-25, Springer, 2005.

Russell III, J. M., Mlynczak, M. G., Gordley, L. L., Tansock Jr, J. J., and Esplin, R. W.: Overview of the SABER experiment and preliminary calibration results, in: SPIE's International Symposium on Optical Science, Engineering, and Instrumentation, 277-288, International Society for Optics and Photonics, 1999.

Soukharev, B. E. and Hood, L. L.: Solar cycle variation of stratospheric ozone: Multiple regression analysis of long-term satellite data sets and comparisons with models, J. Geophys. Res., 111, D20314, doi:10.1029/2006JD007107, 2006.

Terao, Y. and Logan, J. A.: Consistency of time series and trends of stratospheric ozone as seen by ozonesondes, SAGE II, HALOE, and SBUV(/2), J. Geophys. Res., 112, D06310, doi:10.1029/2006JD007667, 2007.

Unruh, Y., Solanki, S., and Fligge, M.: The spectral dependence of facular contrast and solar irradiance variations, Astron. Astrophys., 345, 635-642, 1999.

Wang, H. J., Froidevaux, L., Anderson, J., Schwartz, M., Fuller, R., Bernath, P., Zawodny, J. M., Thomason, L. W., Pawson, S., and Rienecker, M.: Long term stratospheric ozone record obtained by merging $\mathrm{O} 3$ profiles from different satellites, SPARC/WMO Ozone Trend Workshop, Geneva, Switzerland, http://igaco-o3.fmi.fi/VDO/presentations_ 2011/datasets/WS_2011_Wang.pdf, (last access: 25 November 2011), 2011. 
Weber, M., Dhomse, S., Wittrock, F., Richter, A., Sinnhuber, B., and Burrows, J.: Dynamical control of NH and SH winter/spring total ozone from GOME observations in 1995-2002, Geophys. Res. Lett., 30, 1583, doi:10.1029/2002GL016799, 2003.

WMO: Scientific Assessment of Ozone Depletion: 1985, Global Ozone Research and Monitoring Project Report 16, World Meteorological Organization, Geneva, 1985.
Woods, T. N.: Solar irradiance variability: comparisons of observations over solar cycles 21-24, in: EGU General Assembly Conference Abstracts, edited by: Abbasi, A. and Giesen, N., vol. 14, p. 1520, European Geosciences Union, Munich, Germany, 2012. 